Florida International University FIU Digital Commons

$11-6-1995$

\title{
Physical therapy recruitment and retention strategies of hospitals in the US
}

Laura Burgos

Florida International University

DOI: $10.25148 /$ etd.FI14051881

Follow this and additional works at: https://digitalcommons.fiu.edu/etd

Part of the Physical Therapy Commons

\section{Recommended Citation}

Burgos, Laura, "Physical therapy recruitment and retention strategies of hospitals in the US" (1995). FIU Electronic Theses and Dissertations. 1945.

https://digitalcommons.fiu.edu/etd/1945

This work is brought to you for free and open access by the University Graduate School at FIU Digital Commons. It has been accepted for inclusion in FIU Electronic Theses and Dissertations by an authorized administrator of FIU Digital Commons. For more information, please contact dcc@fiu.edu. 
FLORIDA INTERNATIONAL UNIVERSITY

Miami, Florida

PHYSICAL THERAPY RECRUITMENT AND RETENTION STRATEGIES OF

HOSPITALS IN THE US

A thesis submitted in partial satisfaction of the

requirements for the degree of

MASTER OF SCIENCE

IN

PHYSICAL THERAPY

by

Laura Burgos

1995 
To: Judith Blucker

College of Health

This thesis, written by Laura Burgos, and entitled PHYSICAL THERAPY

RECRUITMENT AND RETENTION STRATEGIES OF HOSPITALS IN THE US, having been approved in respect to style and intellectual content, is referred to you for judgement.

We have read this thesis and recommend that it be approved.

Awilda Haskins

Sherry Moss

Leonard Elbaum, Major Professor

Date of Defense: November 6, 1995

The thesis of Laura Burgos is approved.

Dean Judith Blucker

College of Health

Dr. Richard L. Campbell

Dean of Graduate Studies

Florida International University, 1995 


\section{COPYRIGHT 1995 by Laura Burgos}

All rights reserved 
This thesis is dedicated to Geber, Patrick, Daniella and the little one to come (Jordi or Monique). 


\section{ACKNOWLEDGMENTS}

Thanks to everyone who helped me with my thesis ... co-workers, my family

and members of my committee. Special thanks to my major professor, Dr. Leonard Elbaum, for his energetic enthusiasm, valued criticism toward my project and especially for sharing his knowledge and experience. 


\section{ABSTRACT OF THE THESIS \\ PHYSICAL THERAPY RECRUITMENT AND RETENTION STRATEGIES OF \\ HOSPITALS IN THE US}

by

\section{Laura Burgos}

Florida International University, 1995

Professor Leonard Elbaum, Major Professor

Hospitals are seeing a reduction of physical therapy (PT) staff due to increased opportunities and competition. Planning effective recruitment and retention strategies for PTs in hospital settings may play an important role in reducing the problem. The primary purpose of this descriptive research was to compile information on recruitment and retention strategies used for physical therapists working in hospital settings.

Four hundred surveys were mailed nationwide to hospital-based physical therapy managers. Strategies most commonly used were: attractive benefit package, interdisciplinary teams, competitive salaries, and student employment. The least used strategies used were: sign-on bonus, incentive pay programs, recruitment and retention committee and temporary staffing.

It was concluded that hospital administrators need to analyze current strategies used and future recruitment and retention staffing trends, in order to institute successful strategies appropriate to their departments to effectively recruit and retain their staff. 


\section{TABLE OF CONTENTS}

Page

CHAPTER I

Introduction

Statement of the Problem

Purposes of the study 8

Research Questions

8

Significance of the Study

9

CHAPTER II Literature Review

Theoretical and Practical Reasons for the PT Shortage 11

The Cost of PT Vacancies and High Turnover 12

Methods of Recruitment and Retention Strategies of Other Allied Health

Professions

Methods of Recruitment and Retention Strategies for PTs 17

Conclusion

CHAPTER III Methodology

Sample and Subjects $\quad 23$

Survey Instrument 23

Procedure for Data Collection $\quad 24$

Data Analysis $\quad 24$

CHAPTER IV Results

Response Rate $\quad 26$

Demographic Characteristics of Respondents 26

Recruitment and Retention Strategies for Physical Therapists in

Hospital Settings $\quad 37$

Relationship Between Demographic Characteristics and Recruitment and Retention Strategies for PTs in Hospital Settings 44

Summary $\quad 51$

CHAPTER V Discussion

Introduction $\quad 53$

Recruitment and Retention Strategies for PTs in Hospital Settings 54 


\section{LIST OF TABLES}

Page

Table 1. Top Ten Vacancy Rates by Occupation 2

Table 2. Average Time to Fill Full Time Vacancy 3

Table 3. Retention Difficulty for Several Selected Personnel Categories 4

Table 4. Recruitment Difficulty for Several Selected Personnel

Categories 5

Table 5. 1991 AHA Survey of Human Resources - PT Recruitment and Retention Strategies 21

Table 6. Age and Managerial Experience of the Respondents 27

Table 7. Breakdown of Respondents by States and Districts 29

Table 8. Professional Title of Respondents 31

Table 9. Respondents' Profession $\quad 32$

Table 10. Business/Management Education of Respondents 33

Table 11. Business/Management Degrees of Respondents with Business/ Management Education $\quad 34$

Table 12. Type of Hospital 36

Table 13. Recruitment and Retention Strategies

(Responses to Questions 15 - 23) 38

Table 14. Recruitment and Retention Strategies

(Responses to Questions 24 - 28)

Table 15. $\quad$ Categorized Responses to Question 29: "What has been the Most Successful Strategy you have Used to Aid in Recruitment and Retention of PTs? Why?"

Table 16. Results of Chi-Square Analysis of the Relationship between

Business/Management Education and the Use of Flexible

Scheduling Program for PT Staff

Table 17. Results of Chi-Square Analysis of the Relationship between

Business/Management Education and the Use of Sign-On

Bonuses

Table 18. Results of Chi-Square Analysis of the Relationship between

Gender and the Use of Contract PT Services 48

Table 19. Results of Chi-Square Analysis of the Relationship between Gender and the Use of On-Call or Per Diem PTs

Table 20. Results of Chi-Square Analysis of the Relationship between Age of Respondents and the Use of On Call, Per Diem PTs 


\section{Chapter I}

\section{Introduction}

\section{Statement of the Problem}

The demand for physical therapy (PT) services has positioned physical therapy as one of the fastest growing careers in the US. The increase in the elderly population, the increase in the survival rate of people with serious injuries, the passage of legislation requiring the "mainstreaming" of children with disabilities into the public system, and more, have heightened the demand for PT services and have created new opportunities within the PT profession (Russell, 1990)

According to the American Hospital Association's (AHA) 1991 Annual Survey of Human Resources, physical therapists (PTs) ranked first in the top ten occupation vacancy rates. Physical therapists showed a $17 \%$ vacancy rate, occupational therapists (OTs) ranked 2 nd with a $13 \%$, and physician assistant (PAs) 3 rd with a $12 \%$ vacancy rate (See Table 1). Physical therapists also ranked first in average time to fill full time positions (90 days or more), while OTs ranked second and PAs ranked third (See Table 2). Physical therapists ranked second in the most difficult staff to retain (32\%) and recruit (55\%). Staff nurses ranked first in the occupation most difficult to recruit (70\%) and ranked also first in the staff most difficult to retain (73\%). See Tables 3-4. 
Table 1

Top 10 Vacancy Rates, by Occupation: A National Display by Occupation of Vacancy

$\underline{\text { Rates }}$

\begin{tabular}{|c|c|c|c|}
\hline & Full-time & Part-time & FTE \\
\hline Physical Therapist & $16.6 \%$ & $7.1 \%$ & $15.4 \%$ \\
\hline Occupational therapist & $14.2 \%$ & $8.1 \%$ & $13.5 \%$ \\
\hline Physician assistant & $12.8 \%$ & $6.5 \%$ & $12.4 \%$ \\
\hline Radiation therapy tech. & $12.9 \%$ & $6.1 \%$ & $12.4 \%$ \\
\hline Cytotechnologist & $12.8 \%$ & $8.5 \%$ & $12.2 \%$ \\
\hline Speech pathologist & $11.1 \%$ & $6.9 \%$ & $10.5 \%$ \\
\hline Occupational therapy assistant & $10.3 \%$ & $7.1 \%$ & $10.0 \%$ \\
\hline Certified registered nurse anesthetist & $9.4 \%$ & $5.5 \%$ & $9.0 \%$ \\
\hline Nuclear medicine tech. & $8.2 \%$ & $8.4 \%$ & $8.2 \%$ \\
\hline Physical therapy assistant & $8.2 \%$ & $6.6 \%$ & $8.0 \%$ \\
\hline
\end{tabular}

Note. From "AHA's Survey of Human Resources - 1991", A Report by Barbara Bloom Kreml, Director Department of Human Resources. 
Table 2

Average Time to Fill Full Time Vacancy: For Each Occupation, a National Display of the

Percentage of Total Responding Hospitals falling in Each Average Recruiting Time

Interval

\begin{tabular}{|c|c|c|c|c|}
\hline Und & 30 days & 31-60days & 61-90days & $90+$ days \\
\hline Physical therapist & $2.5 \%$ & $13.8 \%$ & $19.6 \%$ & $64.1 \%$ \\
\hline Occupational therapist & 6.6 & 25.8 & 22.0 & 45.6 \\
\hline Physician assistant & 11.8 & 23.6 & 21.3 & 43.3 \\
\hline Radiation therapy tech. & 8.8 & 25.8 & 27.4 & 38.0 \\
\hline Cytotechnologist & 8.3 & 29.1 & 20.8 & 41.9 \\
\hline Speech pathologist & 12.0 & 34.9 & 25.7 & 27.4 \\
\hline Occupational therapist assistant & 26.3 & 35.3 & 19.9 & 18.4 \\
\hline $\begin{array}{l}\text { Certified registered nurse } \\
\text { anesthetist }\end{array}$ & 5.7 & 20.1 & 20.4 & 53.8 \\
\hline Nuclear medicine tech. & 8.8 & 31.1 & 28.2 & 31.8 \\
\hline Physical therapy assistant & 34.6 & 30.5 & 16.7 & 18.2 \\
\hline
\end{tabular}

Note. From "AHA's Survey of Human Resources - 1991", A Report by Barbara Bloom Kreml, Director Department of Human Resources. 
Table 3

Retention Difficulty for Several Selected Personnel Categories: The Percentage of

Hospitals Listings Each Occupation Among the Five Most Difficult to Retain.

Staff nurse

Physical therapist

Radiologic technologist

Medical technologist

Licensed practical vocational

nurse

Pharmacist

Respiratory therapist

Occupational therapist

Nursing aide/assistant

Medical transcriptionist
72.6

31.6

23.5

23.1

19.8

18.0

17.5

14.7

14.2

Note. From "AHA's Survey of Human Resources - 1991", A Report by Barbara Bloom Kreml, Director Department of Human Resources. 
Table 4

Recruitment Difficulty for Several Selected Personnel Categories: The Percentage of Hospitals Listing Each Occupation Among the Five Most Difficult to Recruit.

Staff nurse (RN)

Physical therapist

Pharmacist

Medical technologist

Radiologic technologist

Occupational therapist

Respiratory therapist

Certified registered nurse anesthetist

Nuclear medicine technologist

Ultrasound technologist
69.8

55.3

34.4

32.9

29.9

28.3

21.3

17.9

16.1

15.3

Note. From "AHA's Survey of Human Resources - 1991", A Report by Barbara Bloom Kreml, Director Department of Human Resources. 
The US Department of Labor, Bureau of Labor Statistics Division has categorized the PT profession as the seventh fastest growing occupation in the United States, with a projection by the year 2005 of an 88 percent increase in job positions; resulting in 3,800 new jobs per year (US Department of Labor, Bureau of Labor Statistics, Occupational Employment-Monthly Labor Review, November 1993). Approximately 39,000 new positions in PT are expected by the year 2,000. In contrast, registered nursing is projected to grow by $44 \%$ (Shanahan, 1993). It has also been projected that by the year 2000 , hospitals will account for 27 percent of practice settings (a decrease of 7.5 percent), while employment in offices of other PTs, doctors, and dentists will constitute 35 percent of all jobs (an increase of 14.3 percent), (Shanahan, 1993).

As a result of the disparity between demand and supply, PTs are assured of acquiring jobs in numerous environments with a minimum of effort, negotiation and delay. It has been reported that hospitals are seeing a reduction in the employment base of PTs and high turnover rates have been documented. The shortage of physical therapists had a greater impact on the hospitals (traditionally the largest employer of PTs) due to the wide variety of opportunities and increased competition in today's competitive health care arena (Russell, 1990). Therefore, recruitment and retention of PTs in the hospital setting is a difficult task to manage.

The recruitment and retention of physical therapists in hospital settings has been identified by the American Physical Therapy Association (APTA) as a topic requiring research attention. Results from the 1991 annual survey of human resources $(3,184$ 
community and non-community hospitals), performed by Barbara Bloom Kreml, Director Department of Human Resources of the American Hospital Association (AHA, 1991), showed that the majority of the hospitals reported that worker shortage had remained the same or increased, despite efforts throughout the hospital arena to address the problem. According to the same survey, the most severe labor shortage in 1991 occurred among full-time physical therapy positions, with a 16.6 percent vacancy rate. This was up from 16.4 percent in 1989 . About $64 \%$ of the respondents also reported that physical therapists were "the most difficult" to recruit. According to the results from a 1992 survey performed by the American Physical Therapy Association (APTA), physical therapists are also pursuing other settings where they can become "specialists", have better salaries and more flexibility. Common reasons on why PTs leave hospital settings are: lack of administrative support, low salary and lack of flexible hours (for females). For males the main reasons are: need to specialize with specific population or within an area of practice, lack of administrative support and paperwork (APTA, 1992).

Physical therapists can go into business for themselves or be affiliated with a sports medicine group. In these settings the PT has more autonomy and a greater impact on patient care (Birritteri, 1993). Therefore, recruitment and retention of PTs in hospitals need to become priorities for hospital-based PT directors, hospital administrators and human resources administrators in order to achieve short and long term solutions that will address staff needs and that will help reduce the impact of the shortage on the public and the profession. 
In summary, hospitals are experiencing an increased reduction in the employment base of physical therapists due to changes in today's competitive health care system and increased opportunities for physical therapists in other settings (Russell, 1990). One possible reason for this problem is that the strategies designed to recruit and retain PTs working in mid-to-large size hospital settings have not been identified and analyzed. It is important to study these strategies in order to identify their efficacy.

\section{Purposes of the study}

The primary purpose of this descriptive study was to describe strategies used nationwide to recruit and retain PTs working in mid-to-large size general hospitals. Secondary purposes were to: identify the percentage of respondents reporting problems with the recruitment and retention of PTs within the last year; identify the demographic characteristics of respondents; investigate the relationship of the demographic characteristics of physical therapy department managers to the recruitment and retention strategies used by those managers; and, describe the respondents' opinions on the most successful strategies used to aid in recruitment and retention of PTs.

\section{Research Questions}

The study was descriptive in nature. Therefore a set of research questions was 
developed which the study was designed to answer.

The questions were as follows:

1. What are the strategies used to recruit and retain PTs in hospital settings ?

2. What percentage of respondents reported having problems with the recruitment and retention of PTs within the last year?

3. What are the respondents' demographic characteristics, such as, title, gender, age, educational background, managerial experience, and work environment characteristics (i.e., such as, type of hospital, hospital location, inpatient capacity, and quantity of budgeted and vacant PT positions).

4. What is the relationship between the respondents' demographic characteristics and the recruitment and retention strategies used by the respondent.

5. What do the respondents think are the most successful strategies used to aid in the recruitment and retention of PTs?

\section{Significance of the Study}

Hospital administrators, PT department managers and human resources managers could improve the effectiveness of their recruitment and retention strategies for PTs working in hospital settings by adopting strategies used nationwide, especially those strategies viewed as the most successful ones. Their awareness toward the personnel problem would increase if they were informed about the percentage of respondents 
reporting having problems with the recruitment and retention of PTs in hospital settings. If there was a relationship between the respondents' demographic characteristics and the effectiveness of their recruitment and retention strategies, hospital administrators could use this information to increase competitiveness and better serve health care needs. 


\section{Chapter II}

\section{Literature Review}

\section{Theoretical and Practical Reasons for the PT Shortage}

The demand for physical therapists nationally has been greater than the supply for many years. This demand has positioned PT as a leading "new" field in today's health market place (Russell, 1990).

Reasons for the shortage include the increase in the elderly population. As the elderly population grows, so will the projected need for PTs who rehabilitate patients who have diagnosis associated with aging process, such as, total joint replacements, strokes, and cardiac problems. Currently $67 \%$ of therapists already report treating patients 64 years of age and older on a typical day (Shanahan, 1993). Other reasons for the shortage include the increase in the survival rate of people with serious injuries, due to current medical and technological advances; the passage of legislation requiring the "mainstreaming" of children with disabilities into the public school setting; as spouses' incomes or family responsibilities rise, allied health professionals tend to work less; and the production of an inadequate number of graduates to meet the demand (Russell, 1990). Graduating classes of PT schools have been increasing in size by about 300 students every 2 years, but growth in the number of rehabilitation beds has been faster, and PTs are hired as soon as they graduate. In addition, a nationwide surge in wellness programs and fitness regimes is 
sphoring from the medical field (Koska, 1989).

Some of the factors mentioned above have created new opportunities and increase competition within the physical therapy profession and hospitals are no longer the biggest employers of PTs (Koska, 1989).

Physical therapists typically do not remain employed in hospital settings for a long period of time. The average time of employment of physical therapists in hospital settings is 18 months (APTA Recruitment and Retention of PTs in Hospital-Based Practice, 1989). Poor retention is due to a lack of upward mobility opportunities, a higher intensity workload, lack of administrative support, low salaries, lack of flexible hours, paperwork, and lack of opportunities for clinical specialization (Koska, 1989).

\section{The Cost of PT Vacancies and High Turnover}

There are short-term, long-term and opportunity costs generated by vacancies in staffing (Shanahan, 1993). Costs are very difficult to measure because it is not clear which factors actually result in costs to the institution and which costs are attributable to each factor which may be responsible for generating these difficult-to-quantify costs. Some of these costs are related to the impressions of the facility. Chronically under-staffed facilities develop a "bad name" within the profession, further discouraging potential new employees. The cost to the hospital is reflected through increased amounts of time and 
money devoted to recruiting efforts. Another example of cost could be explained by the lack of continuity of patient care. The possible compromise in quality of care by contract or over-worked employees hinders the ability of the hospital to attract new or previous customers in the long run. Lower quality patient care can also increase the hospital length of stay, thus increasing the costs to the hospital. Loss of revenue could be generated through potential forfeited revenue in PT from patient treatments that are not scheduled as a result of labor shortages. And finally loss of revenue could be created by missed opportunities for long-range program development due to labor shortage. In a 1989 national survey on recruitment costs of PTs, Gandy estimated an average of $\$ 13,191$ per vacant position. This estimate included advertising, interview and orientation costs, and any scholarship money provided. Of this total, an average of $\$ 5,889$ was spent per position on advertising (Shanahan, 1993).

Facilities in the 1989 national survey on recruitment costs of PTs, reported two to three vacancies per year. Assuming that a hospital had two PT vacancies and employed one contract therapist, the annual measurable cost to the hospital was $\$ 110,782$. Lost revenues, in terms of billable patient hours, due to a single PT vacancy, can equal as much as $\$ 156,000$ (assuming 6 billable hours of an 8 -hour workday, at a rate of 1,560 billable hours per year multiplied by an average of $\$ 100$ per billable hour). Should the hospital opt to fill a vacancy with a temporary therapist, the estimated cost of hiring a contract therapist is $\$ 45$ per hour, or approximately $\$ 7,200$ per month, or $\$ 86,400$ per year (Shanahan, 1993). 
These high real costs can be controlled if cost-containment plans are developed that specifically address sources of escalating labor costs, namely the costs associated with staffing shortages. Hospital administrators need to be aware of the short-and long term implications of PT vacancies. The lack of attention given to the PT shortage seems to be driven by the inability of the hospital to quantify the indirect and opportunity costs created by the labor shortage. Adequate data are not available to quantify the amount of PT a patient receives as it relates to the costs associated with the length of stay or providing care for patients at a lower level of function, or to quantify how these costs are impacted by inadequate levels of PT staffing (Shanahan, 1993).

\section{Methods of Recruitment and Retention Strategies of Other Allied Health}

\section{Professions}

The nursing shortage caused hospital administrators to address these issues for an extended period. This shortage plagued the profession during the mid-to-late $1980 \mathrm{~s}$. The nurse vacancy rate, fluctuating between $17-18$ percent five years ago, today stands at 5.6 percent, and at some institutions the level is as low as 1.2 percent (Birritteri, 1993).

Recruitment and retention deterrents in the nursing field were researched and analyzed. Hospital administrators used this information and were able to create successful recruitment and retention strategies. Example of successful strategies were: flexible scheduling, promotion system rewarding clinical excellence and productivity (i.e., 
obtaining national certification), participative management of staff nurses in the development of policies and procedures and strategic planning, shared governance, available day care, competitive salaries and tuition reimbursement, financial assistance for RNs attending continuing education, financial assistance for LPNs/LVNs seeking to become $\mathrm{RN}$, financial support for $\mathrm{RN}$ in degree seeking programs and financial incentives for less desirable work shifts (Birritteri, 1993).

Career ladder programs were considered a successful strategy used to retain experienced nurses. One study demonstrated that nurses on the clinical ladder program held slightly more positive attitudes about job satisfaction, promotional opportunities and work rewards and had a lower intent to leave (Corley et al, 1994).

Compensation is another strategy used to recruit and retain nurses. This strategy recognizes nurse expertise. Several pilot studies have found decreased costs, less use of sick hours and staff nurse turnover, elimination of external agency costs and improved documentation quality by increasing salaries (Corley et al, 1994).

Empowerment is a strategy used to retain nurses through encouraging participatory management and increased autonomy. As a result of this strategy, studies showed an increase of staff morale and increased accountability and professionalism. There was also an improvement in the quality of written documentation, and sick time usage dropped (Khan and Konsones, 1992).

Recognition and reward programs such as "Professional Excellence in Nursing" (PEN) represent another type of strategy that recognizes and rewards practice excellence 
of the nurse involved in direct patient care. This program was effective in promoting behavior of professionalism by encouraging collegiality initiative, creativity, continued learning and self-direction (Bauer et al, 1993).

The use of technology in the form of automation and telecommunication is essential to the development of a positive, professional environment that successfully recruits and retains nurses. Examples of this technology are: bed side, or point of care terminals; automated skill mixed determination; telecommunication systems and automated resource scheduling system. Results of two studies on bed terminals revealed that the use of these terminals affected the professional nursing environment in five ways: decreased work load, improve quality of care, increased positive public relations, improved communication and increased positive perception of administration (Adamski, and Hagen, 1990).

One of the top strategies used to recruit and retain licensed practical/vocational nurses (LPN/LVN), medical laboratory technicians, pharmacists and staff nurses was the use of "innovative scheduling", (AHA, 1991).

Results from a study on retaining occupational therapists (OTs) in rehabilitation settings, showed that there were factors related with job satisfaction that influenced OTs in their decision to remain employed in rehabilitation settings. Patient care and program development were seen as rewarding aspects of their jobs and paperwork was seen as the most stressful aspect of their jobs (Freda, 1991). 


\section{Methods of Recruitment and Retention Strategies for Physical Therapists}

There is little published research on the effectiveness of recruitment and retention strategies of PTs in hospital settings. A study was conducted by the Michiana Rehabilitation Institute (MRI) at Memorial Hospital of South Bend, Indiana on the use of the career ladder. MRI developed a recruitment and retention strategy whose goals were to improve the quality of patient care, stabilize the current work force, reduce the turnover rate and fill budgeted positions through the integration of a career ladder concept into the allied health care recruitment process. This strategy or program was named "Advancement for Clinical Excellence" (ACE). The program recognized individual professional staff competency within the context of meeting specific job requirements and providing monetary incentives for advancement in the program. The program is currently in practice and its efficacy has not been documented yet, but the program anticipates improved success in hiring and retaining quality employees (Strakal, and Egli, 1993).

Michiana Rehabilitation Institute - Comprehensive Rehabilitation Services and Administration (CRSA) section, also developed a set of strategies to aid their staffing crisis and high turnover rates that exceeded the national average turnover rate. CRSA ended its staffing crisis by targeting strategies and capitalizing on its strengths. Examples of these strategies were the identification of department's missions, the creation of a team philosophy, and the implementation of a participatory management (decision making power is delegated downward, as close to the problem level as possible). An open door 
policy was adopted by the management team and there was participation of staff in program development. Marketing strategies included brochures, open houses and luncheons for case mangers from referring agencies and offering hour-long seminars on topics relevant to their interests. MRI-CRSA put in place a reward system, which included: merit pay system rewarding staff for their exemplary performance in the clinic and for their contributions to program development and recruitment activities; staff education programs (recruitment and retention topics are discussed at monthly staff meetings to bolster MRI - CRSA philosophy); staff recruitment and retention survey; continuing education; promotion of social activities; expansion of clinical affiliation programs; and, a student loan program. Results of these strategies showed a decrease in turnover rates from greater than 20 percent to about 14 percent, and vacancy duration time also decreased from 3-6 months to 4-6 weeks (Strakal, 1990).

Another strategy used by hospitals to maintain optimal staff levels and effectively recruit and retain their staff has been the hiring of personnel who are registered with agencies in the private sector. A study was conducted to examine the degree to which the shortage of PTs in San Diego had affected local hospitals, to assess current use and cost of registry personnel and to examine the advantages and disadvantages of temporary staffing through PT registries. It was concluded that registries can facilitate personal advances for PTs, but the use of registries to supplement a hospital's permanent PT staff has proven to be exceedingly expensive, lacks ongoing continuity for the patient, and produces a somewhat disruptive administrative environment within the hospital. 
Suggestions from this study were for hospital administrators to plan innovative ways to recruit and retain personnel through improvements in compensation, creative benefits packages, flexible working hours, opportunities to participate in management discussions and other issues related with the working environment (Russell, Seidman, and Williams, 1990).

A unique recruitment and retention strategy for PTs was performed by a group of hospitals in the Dayton area. Ten hospitals in the Dayton area banded together to bring PTs to their region. They joined their financial forces and unified their recruitment goals. This recruitment task force developed aggressive advertising strategies to market their hospitals, the Greater Dayton area, and the Southwest Ohio area. Because this type of strategy falls into the category of one-of-a-kind operation, its long term success was difficult to predict. In terms of immediate success, it was a cost saving move for each of the participating hospitals (Breske, 1993).

According to the American Hospital Association's (AHA) 1991 annual survey of 1927 urban hospitals, the following strategies were reported as the top three strategies used in recruitment and retention of PTs in urban hospitals: changes in compensation programs (641); scholarship/forgivable loan (472); and sign-up bonus (461). The least used strategies were: career mobility (247); foreign recruitment (177); and restructuring jobs (108) (Table 5). It appears that the most common strategies used in urban hospitals to recruit and retain PTs do not coincide with the successful strategies (i.e., autonomy, flexibility, program development, upward mobility, creativity, job restructuring) used in 
nursing to alleviate the shortage. 
Table 5

1991 AHA's Survey of Human Resources - PT Recruitment and Retention Strategies

Strategies:

Hospitals Reporting

Changes in compensation programs

641

Scholarship/forgivable loan

472

Sign - up Bonus

461

Contract services

392

Incentive pay benefit

376

Student employment

Innovative scheduling

293

On call/pool staff

328

Overtime

Temporary staff 257

Career mobility

Foreign recruitment

177

Restructuring of jobs 108

Total urban hospitals responding 1927

Note. From "AHA's Survey of Human Resources - 1991", A Report by Barbara Bloom Kreml, Director Department of Human Resources. 


\section{Conclusion}

In conclusion, hospitals are using recruitment and retention strategies that may not be necessarily sensitive to staff needs in today's competitive health care environment. Hospital administrators need to increase their awareness of the adverse effects of the shortage and the negative consequences to the staff that remains employed in hospital settings. They could learn from the solutions adopted by the nursing field, since there is significantly more published research, and extrapolate them to the PT field. Hospitals must also be aware that the effectiveness of these strategies is determined by how well the hospital can address the concerns of its therapists (Shanahan, 1993). 


\section{CHAPTER III}

\section{Methodology}

\section{Sample and Subjects}

Four hundred surveys were sent to PT department managers employed at general hospitals with bed capacities of at least 300 beds. The hospitals were selected at random from the 1995 Hospital Phone Book (US Directory Service, 1995).

\section{Survey Instrument}

The survey instrument consisted of self identification questions, forced-choice questions (true or false and yes or no), Likert scale questions and one open-ended question (Appendix A)

The cover letter enclosed with the survey contained information on the purpose of the study, the average time to complete survey, and mailing procedures. A phone number was included if extra clarification or information was needed. Assurance of anonymity was confirmed. An offer to mail the survey results to the respondents was included.

The self-identification questions requested information on the manager's professional title, gender, age, education, and managerial experience. They also requested information on the type of hospital, inpatient bed capacity and quantity of budgeted and 
vacant PT positions. The forced "yes or no" question was designed to acknowledge if there was a problem or not with recruitment and retention of PTs within the last year (1994). The true or false and Likert scale questions were designed to identify recruitment and retention strategies of PTs used in hospital settings. The survey concluded with one open-ended question that requested information on the most successful strategy used to aid in the recruitment and retention of PTs.

Although no formal reliability or validity testing was performed, a draft of the survey instrument was reviewed by faculty members of the Physical Therapy and Management departments at Florida International University and in this way face-validity of the instrument was achieved.

\section{Procedure for Data Collection}

On March 13, 1995, the survey instrument accompanied by a cover letter, along with a self-addressed, stamped envelope, was mailed to 400 potential respondents. No deadline date was announced in the cover letter. Instead respondents were asked to return the survey at their earliest convenience.

\section{Data Analysis}

The analysis of the data was initiated after five consecutive days of not receiving 
more surveys ( 28 days after mailing). Responses were coded and entered into a computerized database Quattro Pro, Novell Perfect Office Version 6.01 for Windows 1993, 1994 (Novell Inc., Orem, Utah). SPSS-PC, Statistical Programs for the Social Sciences, Version 6.2 (SPSS, Inc. Chicago, IL) was used to compute descriptive statistics for the self-identification items. Cross tabulations were used to examine the relationship between respondents' demographic characteristics and recruitment and retention strategies of PTs used in hospital settings. To assess the strength of association of these relationships, chi-square statistical procedures were done. Responses to the open-ended question were categorized based on author's judgement. Many of these responses were similar and were grouped into 46 different categories. These responses were grouped according to likeness and fitness of content to the appropriate category. The most prevalent categories, (12 categories with 464 strategies), were analyzed and the less prevalent categories (34 with 86 strategies), were excluded from the analysis. Therefore, only 12 categories with 464 strategies were analyzed $(550-86=464)$. 


\section{CHAPTER IV}

\section{Results}

\section{Response Rate}

On March 13, 1995, 400 surveys were mailed and on April 14, 1995, a total of 269 surveys were collected. This translates to a response rate of $67.2 \%$. Of the 269,13 were excluded because they did not meet the criteria for hospital selection.

\section{Demographic Characteristics of Respondents}

Females accounted for $69.8 \%$ (178) and males for a $30.2 \%$ (77) of the respondents. The age of the respondents ranged between $24-72$ years old with a mean age of 40.9 and a mean of 8.5 years of managerial experience. Age and managerial experience are summarized in Table 6. 
Table 6

Age and Managerial Experience of the Respondents (in Years)

\section{Mean SD Minimum Maximum Range}

$\begin{array}{llllll}\text { Age } & 40.9 & 8.6 & 24.0 & 72.0 & 48.0\end{array}$

$\begin{array}{llllll}\text { Managerial Experience } & 8.5 & 7.2 & 0.1 & 39.0 & 38.9\end{array}$ 
Responses were obtained from 39 states and districts. The greatest number of respondents came from hospitals in New York, Florida, Pennsylvania, Illinois, Ohio, New Jersey, California, Texas, Michigan and Tennessee. (See Table 7) . 
Table 7

Breakdown of Respondents by States and Districts (Cells With Multiple State Listings Show Each State had the Number of Respondents listed.)

$\begin{array}{lll}\text { State } & \text { Percentage of Sample } & \text { Frequency }\end{array}$

New York

8.2

Florida

7.0

18

Pennsylvania

6.6

17

Illinois, Ohio

6.3

16

New Jersey

5.9

15

California, Texas

5.5

14

Michigan

5.1

13

Tennessee

4.7

12

Maryland

3.1

8

Indiana, North Carolina

2.7

7

Alabama, Georgia, Massachusetts

2.3

6

Missouri

2.0

5

Iowa, Minnesota, Mississippi

1.6

4

South Carolina, Washington

Wisconsin

Arizona, Connecticut, Kansas,

Louisiana, Nebraska

District of Columbia, Nevada,

0.8

Oklahoma, Oregon, Virginia

Colorado, Delaware, Kentucky,

0.4

1

Maine, Puerto Rico, West Virginia

Alaska, Arkansas, Hawaii, Idaho

0.0

0

Montana, New Hampshire, New

Mexico, North Dakota, Rhode Island,

South Dakota, Utah, Vermont, Virgin Island, Wyoming 
Of the respondents, $49 \%$ (125), indicated that their professional title was Chief or Director of Physical Therapy, followed closely by Administrator of Rehabilitation Services, 36.1\% (92). Physical Therapy Supervisor constituted 5.1\% (13), Director of Acute Care Therapy Services 3.9\% (10) and Director of Physical and Occupational Therapy $2.7 \%$ (7). (Table 8 ).

Ninety two percent were physical therapists. Four percent (11) were occupational therapists; $1.6 \%(4)$, were speech pathologists, and $0.8 \%(2)$ were administrators. (Table 9).

Of those who were physical therapists, the majority $(57.3 \%$ or 143$)$ indicated that their highest level of education was a bachelor's degree. Thirty five percent had master's degrees, and $7.7 \%$ (18) held certificates of completion from a PT program, not academic degrees.

Most of the respondents did not have formal business or management education (Table 10). Seventy seven percent (194), had no business/management education. Of the $23.3 \%$ (59) that had business or management education, $35.6 \%(21)$ had a Master's in Business Administration; 27.1\% (16) had a Master's in Health Sciences, and 5.1\% (3) had a Bachelor's in Business Administration (Table 11). 
Table 8

Professional Title of Respondent

Percentage

Frequency

of sample

Chief/Director of PT

49.0

125

Administrator of Rehab

36.1

92

Services

PT supervisor

5.1

13

Director of Acute Care

3.9

10

Therapy Services

Director of PT and OT

Clinical Specialist/Education

1.6

4

Other

1.6

4 
Table 9

Respondent's Profession

Other 
Table 10

Business/Management Education of Respondent

Percentage

Frequency

of Sample

No Business/Management Education

76.7

194

Business/Management Education

23.3

59 
Table 11

Business/Management Degrees of Respondents with Business/Management Education

Percentage of Sample

Frequency

Master's in Business Administration

35.6

21

Master's in Health Sciences Administration

27.1

16

Bachelor's in Business Administration

5.1

3

Other

32.2

19 
The number of PT budgeted positions ranged from $2-70$ with a mean of 16 and a mode of 10. Of these budgeted positions, the number of PT vacant positions ranged from 0 - 13.6 with a mean of 1.76 PT vacant positions. Most of the respondents, $36.2 \%(92)$, had no PT vacant positions, followed by $20.1 \%$ (51) for one position and $17.3 \%$ (44) for two vacant PT positions.

General hospital beds ranged between $300-1567$ with a mean of 583.15 beds.

Sixty-eight percent (174) of the facilities were private-not for profit hospitals; $4.7 \%$ (12) were investor owned hospitals; $14.1 \%$ (36) were state or local government owned hospitals; 7.8\% (20) were Federal, Veterans Administration hospitals; and 5.1\% (13) were other type of hospitals (Table 12) . 
Table 12

Type of Hospital

Percentage of Sample

Frequency

Private, not for profit

68.2

174

State or Local Government owned

14.1

36

Federal, Veteran's Administration

7.8

20

Private, investor owned

4.7

12

Other

5.1

13 


\section{Recruitment and Retention Strategies for PTs in Hospital Settings}

Fifty-nine and two tenths percent $(59.2 \%)$, or 151 , of the respondents indicated having problems with recruitment and retention of PTs within the last year and $40.8 \%$ (104) responded as having no problems.

In questions 15 through 23 , the respondents had to respond true or false to different statements concerning recruitment and retention strategies. The most commonly strategies used were: attractive benefit package (234), interdisciplinary team (216) and competitive salaries (210). The least commonly occurring responses were: sign-on bonus (110), incentive pay programs (60) and recruitment and retention committee (41) (Table 13). 
Table 13

Recruitment and Retention Strategies (Responses to question 15-23)

$\begin{array}{ll}\text { Percentage } & \text { Frequency } \\ \text { of Sample } & \end{array}$

Strategies:

\begin{tabular}{|c|c|c|}
\hline Attractive Benefit Package & 92.5 & 23 \\
\hline Interdisciplinary Teams & 85.0 & 210 \\
\hline $\begin{array}{l}\text { Competitive Salaries } \\
\text { (adjusted in a yearly basis) }\end{array}$ & 82.4 & 210 \\
\hline $\begin{array}{l}\text { Specialized Clinical } \\
\text { Assignments }\end{array}$ & 81.2 & $20^{7}$ \\
\hline Flexible Scheduling Programs & 68.1 & 173 \\
\hline Formal Career Ladder Policy & 52.0 & 133 \\
\hline Sign-on Bonuses & 43.0 & 110 \\
\hline Incentive Pay Programs & 23.6 & 60 \\
\hline $\begin{array}{l}\text { Recruitment and } \\
\text { Retention Committee }\end{array}$ & 16.0 & 41 \\
\hline
\end{tabular}


In questions 24 through 28 , respondents had to determine whether they had never, seldom, occasionally, frequently or always used the recruitment and retention strategies.

The strategy least used or never used was on-call, per diem staff (117), while the strategy most frequently used was student employment (114), (Table 14). 
Table 14

Percentage of Respondents that used Recruitment and Retention (Responses to questions $\underline{24-28)}$

\begin{tabular}{|c|c|c|c|c|c|}
\hline \multirow[b]{2}{*}{ Strategies } & \multicolumn{5}{|c|}{ Never Seldom Occasionally Frequently Always } \\
\hline & & & $\begin{array}{l}\text { rcenta } \\
\text { requen }\end{array}$ & & \\
\hline $\begin{array}{l}\text { We use on-call, per diem } \\
\text { staff }\end{array}$ & $\begin{array}{l}45.7 \\
117\end{array}$ & $\begin{array}{l}10.5 \\
27\end{array}$ & $\begin{array}{l}18.4 \\
47\end{array}$ & $\begin{array}{l}19.9 \\
51\end{array}$ & $\begin{array}{l}5.5 \\
14\end{array}$ \\
\hline $\begin{array}{l}\text { We have scholarship and/or } \\
\text { forgivable loan program }\end{array}$ & $\begin{array}{l}37.6 \\
96\end{array}$ & $\begin{array}{l}4.7 \\
12\end{array}$ & $\begin{array}{l}11.4 \\
29\end{array}$ & $\begin{array}{l}16.5 \\
42\end{array}$ & $\begin{array}{l}29.8 \\
76\end{array}$ \\
\hline We use contract PT Services & $\begin{array}{l}31.8 \\
81\end{array}$ & $\begin{array}{l}21.6 \\
55\end{array}$ & $\begin{array}{l}25.5 \\
65\end{array}$ & $\begin{array}{l}17.3 \\
44\end{array}$ & $\begin{array}{c}3.9 \\
10\end{array}$ \\
\hline $\begin{array}{l}\text { We use aggressive recruitment } \\
\text { advertising }\end{array}$ & $\begin{array}{l}9.4 \\
24\end{array}$ & $\begin{array}{l}22.3 \\
57\end{array}$ & $\begin{array}{l}41.4 \\
106\end{array}$ & $\begin{array}{l}18.4 \\
47\end{array}$ & $\begin{array}{l}8.6 \\
22\end{array}$ \\
\hline $\begin{array}{l}\text { We hire students that performed } \\
\text { their clinical affiliations with us }\end{array}$ & $\begin{array}{l}.8 \\
2\end{array}$ & $\begin{array}{l}6.7 \\
17\end{array}$ & $\begin{array}{l}39.0 \\
99\end{array}$ & $\begin{array}{l}44.9 \\
114\end{array}$ & $\begin{array}{l}8.7 \\
22\end{array}$ \\
\hline
\end{tabular}


The last question was an open-ended question. Respondents were asked: "What has been the most successful strategy you have used to aid in recruitment and retention of PTs?". Although the question asked for "the" most successful strategy, not strategies, most of the respondents responded more than one strategy. Therefore, a total of 550 strategies were mentioned. Many of these strategies were similar and were grouped into 46 different categories. These strategies were grouped according to likeness and fitness of content to the appropriate category. The most prevalent categories, (12 categories with 464 strategies), were analyzed and the less prevalent categories (34 with 86 strategies), were excluded from the analysis. Therefore, only 12 categories with 464 strategies were analyzed $(550-86=464)$. Results from the open-ended question, "What has been the most successful strategy you have used to aid in recruitment and retention of PTs?", showed that the following four strategies were felt by the respondents to be the most successful strategies:

1. "attractive benefit package" - mentioned by $22.2 \%(103)$ of the respondents. (Includes: continuing education, tuition assistance programs, retention bonuses, sign on bonuses, on-site child care, excellent salary, flexible hours, opportunities for extra income for example home health, fee for service programs after working hours, recruitment bonuses, retirement plans.)

2. "good" student program - mentioned by $19.2 \%(89)$ of the respondents.

3. professional development opportunities - mentioned by $15.5 \%$ (72) of the respondents. (Includes: opportunities to develop clinical expertise, career ladder, 
participative management, empowerment and autonomy.)

4. advertising - mentioned by $10.3 \%(48)$ of the respondents. (Includes:

advertising in journals, major markets, student listing, job fair, networking, professional meetings, annual open house for students.)

Formal hiring process occupied the last place with $3.2 \%(15)$ of the respondents considering this strategy as successful. (Includes: interview team, selection of "good" PTs, excellent support from human resource department, continuous recruitment even if no positions are open.) See Table 15. 
Table 15

Categorized Responses to Question \# 29: "What has been the most successful strategy you have used to aid in recruitment and retention of PTs?"

\section{Percentage of sample Frequency}

\section{Strategies}

Attractive benefit package

22.2

103

"Good" student program

19.2

89

Professional development opportunities

15.5

72

Advertising

10.3

48

Scholarship program

Varied clinical experience

6.5

30

Mentor ship program

4.3

20

Rotations of new graduates

3.9

18

Hospital/Department reputation,

Good working environment

Team approach - energetic staff

Formal hiring Process 


\section{The Relationship between Demographic Characteristics and Recruitment and Retention Strategies for PTs in Hospital Settings.}

Chi-square statistical analyses were computed to assess the association and the relationship between respondents' demographic characteristics (age, gender, level of education, business or management education, and managerial experience) and recruitment and retention strategies of PTs in hospital setting (formal career ladder, attractive benefit package, incentive pay programs, flexible scheduling, interdisciplinary teams, clinical assignments, competitive salaries, sign on bonuses, recruitment and retention committee, contract PT services, on-call, per diem PTs, scholarship and/or forgivable loan program, aggressive recruitment advertising and hiring students).

Statistically significant associations were obtained for the relationship between business education and questions 18 and 22, "We have a flexible scheduling program for our PT staff" and "We offer sign-on bonuses." Flexible scheduling was used by $81.4 \%$ of those with formal business education, and by $64.9 \%$ of those without formal business training. Offering sign-on bonus strategy was used by $57.6 \%$ of those respondents with formal business education and by $39.4 \%$ of those without formal business training.

There was also a statistically significant association between gender and questions 24 and 25, "We use contract PT services" and "We use on-call, per diem PTs". Contract PT services was "never"used by $42.9 \%$ of male respondents and occasionally used by only $27.7 \%$ of female respondents. The use of on-call, per diem PTs was classified 
as never used by $51.9 \%$ male respondents and by $43.3 \%$ for female respondents. A statistically significant association was also observed between age and "We use on-call, per diem PTs." Respondents between the age of 35-45 responded never using this strategy (49.6\%) and only $2.4 \%$ of the same age group responded always using this strategy.

Please refer to the next set of Tables $16-20$. 
Table 16

Results of Chi-Square Analysis of Association Between Formal Business/Management

Education and the Use of Flexible Scheduling Program for PT staff (Response to question 18).

"We have a flexible scheduling program for our PT staff"

True

False

Business/Management Education

Yes

48

11

$(27.9)^{*}$

$81.4 \% * *$

18.6

No

Chi-square $=5.67, \mathrm{df}=1, \mathrm{p}=0.01$

* $\quad$ Expected frequencies

** Percentage of row variable responses in this category 


\section{Table 17}

Results of Chi-Square Analysis of the Association Between Formal Business/Management Education and the Use of Sign on Bonus, as a Recruitment and Retention Strategy (Response to question 22).

"We offer sign - on bonuses"

Business/Management Education

Yes

No

60.6

Chi-square $=6.11, \mathrm{df}=1, \mathrm{p}=0.01$

* $\quad$ Expected frequencies

** $\quad$ Percentage of row variable responses in this category 
Table 18

Results of Chi-Square Analysis of the Association Between Male and Female Respondents and the Use of Contract PT Services (Response to question 24).

Never Seldom Occasionally Frequently Always

Gender

Male

33

14

15

10

5

$(40.7)^{*}$

(25.5)

$(23.4)$

(22.7)

(50.7)

$(42.9 \%)^{* *}$

$18.2 \%$

$19.5 \%$

$13.0 \%$

$6.5 \%$

Female

$$
48
$$

41

49

34

5

(59.3)

(74.5)

(76.6)

(77.3)

(50.0)

$27.1 \%$

$23.2 \%$

$27.7 \%$

$19.2 \%$

$2.8 \%$

Chi-square $=9.25 \quad \mathrm{df}=4 \quad \mathrm{p}=0.05$

* $\quad$ Expected frequencies

** Percentage of row variable responses in this category 
Table 19

Results of Chi-Square Analysis of the Association Between Male and Female Respondents and the Use of On-Call, Per Diem PTs (Response to question 25).

Never Seldom Occasionally Frequently Always

Gender

Male

40

12

14

10

1

$(34.2)^{*}$

$(44.4)$

(29.8)

(20.0)

(7.1)

$(51.9)^{* *}$

$15.6 \%$

$18.2 \%$

$13.0 \%$

$1.3 \%$

Female

77

15

33

40

13

$(65.8)$

(55.6)

(70.2)

$(80.0)$

(92.9)

$43.3 \%$

$8.4 \%$

$18.5 \%$

$22.5 \%$

$7.3 \%$

Chi-square $=9.5 \quad \mathrm{df}=4$

$$
\mathrm{p}=0.05
$$

* $\quad$ Expected frequencies

** Percentage of row variable responses in this category 
Table 20

Results of Chi-Square Analysis of the Association Between Age of Respondents and the Use of On-Call, Per Diem PTs (Response to question 25).

Never Seldom Occasionally Frequently Always

Age category

$24-34$

19

5

15

10

8

$(16.7)^{*}$

(19.2)

(32.6)

(20.4)

(57.1)

$(33.3 \%)^{* *} \quad 8.8 \%$

$26.3 \%$

$17.5 \%$

$14.0 \%$

$35-45$

63

4

22

25

3

(55.3)

(53.8)

(47.8)

(51.0)

(21.4)

$49.6 \%$

$11.0 \%$

$17.3 \%$

$19.7 \%$

$2.4 \%$

46 and up $\quad 32$

7

9

14

3

(28.1)

(26.9)

(19.6)

(28.6)

(21.4)

$49.2 \%$

$10.8 \%$

$13.8 \%$

$21.5 \%$

$4.6 \%$

Chi-square $=15.4 \quad \mathrm{df}=8 \quad \mathrm{p}=0.05$

* $\quad$ Expected frequencies

** Percentage of row variable responses in this category 


\section{Summary}

The results of the survey showed that most of the respondents were female PTs with professional title, "Chief or Director of Physical Therapy." The average years of managerial experience was 8.5 and the mean age was 40.9 years old. Of those respondents that were PTs, the great majority showed no formal business or management education and the highest level of education was Bachelor of Science in Physical Therapy. The greatest number of respondents came from hospitals in New York, Florida and Pennsylvania.

Overall, little association existed between the respondents' demographic characteristics and recruitment and retention strategies of PTs in hospital settings. The most common strategies used in recruitment and retention of PT in hospitals settings were: attractive benefit package, interdisciplinary teams, and competitive salaries. The least used strategies were: sign-on bonus, incentive pay programs and recruitment and retention committee. From the results of the Likert scale, the most "frequently" used strategy was student employment and the most often "never" used strategy was hiring oncall/per diem staff. Most of the respondents indicated that an attractive benefits package, a "good" student program and professional development opportunities were the most successful strategies employed to recruit and retain PTs in hospitals.

Statistically significant associations existed between respondents with business education and flexible scheduling program and sign-on bonuses; between gender and 
contract PT services, on-call and per diem PTs; and, between age and on-call and per diem PTs. 


\section{Chapter V}

\section{Discussion}

\section{Introduction}

The purpose of the study was to answer the following questions:

1. What were the recruitment and retention strategies used for PTs working in hospital settings?

2. What was the percentage of respondents reporting problems with recruitment and retention of PTs within the last year?

3. What were the respondents demographic characteristics, including work environment?

4. What were the relationships between respondents' demographic characteristics and recruitment and retention strategies?

5. What were the respondents' opinions on the most successful strategies used to aid in recruitment and retention of PTs? 


\section{Recruitment and Retention Strategies for PTs in Hospital Settings}

Most of the strategies used by general mid to large size hospitals to recruit and retain PTs were: attractive benefit package, interdisciplinary team approach, competitive salaries adjusted in a yearly basis and student employment. Seventy-nine percent (79\%) of the PTs surveyed by the APTA 1992 study on recruitment and retention of PTs in hospital-based practice, classified "benefits" as one of the factors contributing to job satisfaction for PTs who remained in hospital settings and pay was ranked number five on the list of the seven work satisfaction factors.

An excellent source of student employment are clinical education programs.

Hafferty and Goldberg, 1986, found that among students in nonphysician health fields, the clinical education experience was the single most important predictor of the ability of the hospital to retain the new graduate as an employee. Clinical programs can serve two purposes in helping to reduce recruitment and retention costs to hospitals: (1) new employees may become better matched to the job, and (2) costs to the hospital are lower because former students are more likely to return to the facility and remained employed there.

When the respondents were asked to express their opinions on the most successful strategies used to aid in the recruitment and retention of PTs, they responded - attractive benefit package, "good" student program and professional development opportunities. We can see again that attractive benefit package and "good" student program are not only 
frequent observations but also successful ones as viewed by the respondents of this study.

The strategies "sign on bonus" and scholarship/forgivable loans were considered common strategies in the results of the 1991 AHA annual survey to human resources, but in this study they were not considered common strategies. Indeed they occupied the list of the least used strategies in the recruitment and retention of PTs in hospital settings.

Formal career or clinical ladder has been considered a successful strategy used by nurses to increase autonomy and job satisfaction, therefore retaining experienced nurses and improving quality (Corley et al, 1994). In this research $52 \%$ of the respondents responded using this strategy.

\section{Respondents Reporting Problems with Recruitment and Retention of PTs}

Approximately $60 \%$ of the respondents reported having problems and $40 \%$ responded having no problems with recruitment and retention of PTs in 1994. It was expected that a greater percentage of respondents would report having problems with recruitment and retention of PTs in 1994. It is possible that this did not happen due to new trends in the PT profession, such as the employment of PTs increasing at slower rates, salaries not rising at the velocity of past years, effects of managed care in hospital staffing trends, and increased foreign recruitment in specific states for less desirable settings/locations (Murphy, 1995). There has certainly been an increase in the number of physical therapists entering the field and also in the number of new graduates working 
with the geriatric population because of the diversification into more rehab-driven therapy and higher compensations. While the profession is still growing, some recruiters feel that the current growth won't be what it used to be. Recruiting might be getting easier because demand seems to be getting closer to the supply (Murphy, 1995). These new trends merit new research for further analysis.

\section{Demographic and Work Environment Characteristics}

During the process of reviewing the literature, no data was found on demographic characteristics of PT department managers. This data indicates that females continue to dominate the field, despite the increase of males into the profession. Consistent with data from the Bureau of Labor Statistics that about two thirds of PTs are female, this study found that two thirds of managers were females. The respondents of this study were older with a mean age of 41 years old, compared to 36.5 for PTs as a whole. The great majority did not have formal management/business education.

One possible reason why PTs may not have formal business education may be that PTs have increased opportunities in the health care field with increased salaries, opportunities and job security within the profession due to the increase demand.

Therefore, they may not see the need to enter into another highly competitive field such as business/management. Also since the majority of the respondents were females, they might also have family responsibilities making it even more difficult to reenter the academic 
arena.

Most of the respondents worked in private, not for profit, hospitals. The mean inpatient bed capacity was of 583 beds. The mean of budgeted PT positions was 16 , and 10 was the most frequent occurrence. The mean of vacant PT positions was 1.76 , and zero was the mode.

\section{The Relationship between Respondents Demographics Characteristics and}

\section{Strategies used in Recruitment and Retention for PTs employed in hospital settings}

Statistically significant correlation coefficients were obtained for the association between respondents with formal business education and the following strategies: "flexible scheduling program for PT staff" and "sign-on bonus." Managers formally educated in the business/management field are trained in managing personnel. Therefore strategies, such as, "flexibility" and "sign on bonus" might have been analyzed as "key" strategies to recruit and retain PTs. This is consistent with findings from a study of 429 nurses in Hawaii, where "flexibility" is on the list of the top three priorities in the process of recruiting and retaining nurses (Corley et al., 1994).

There is a significant relationship between gender and the following strategies: contract PT services and on-call, per diem PTs. Male PT department mangers tend not to use temporary staffing. Forty-three percent $(43 \%)$ of male PT department managers responded never using temporary staff versus $27 \%$ of female managers responding "never" 
using temporary staff (on-call, per diem, contract). Is it possible that males might be less aware or sensitive to the possible complaints of overworked staff and burnout signs, therefore not requesting the use of temporary staff to alleviate possible staffing crisis? Or is it possible that men are more effective than female managers in recruiting and retaining staff, therefore not requiring temporary staff?

There is also a significant relationship between age and "on-call, per diem PTs." It appears that more experienced PT department managers do not have the need to use temporary staff to alleviate the PT shortage. The reason behind this may be that through experience these mangers have learned to create innovative strategies suitable to their staff needs. Therefore their work force is stable, and there is no need for temporary staffing.

\section{Improving Recruitment and Retention of PTs in Hospital Settings}

Hospitals are using recruitment and retention strategies that may not be necessarily sensitive to staff needs in today's competitive health care environment. Hospital administrators could learn from the solutions adopted by the nursing field, since there is significantly more published research, and extrapolate them to the PT field. Hospital administrators must also be aware that the effectiveness of these strategies is also determined by how well the hospital can address the concerns of its therapists (Shanahan, 1993).

The nursing profession's initial recruitment and retention efforts was through the 
creation of a task force and a literature-based retention survey (Ames et al, 1992). After analyzing results of the retention survey, this nursing services task force was able to identify dissatisfying issues among their work environment and consequently this task force was able to tailor strategies sensitive to staff needs.

As mentioned earlier, there is limited amount of research on the effectiveness of recruitment and retention strategies for PTs in hospital settings, therefore suggestions to improve recruitment and retention of PTs, will tend to be based on the effectiveness of studies previously performed in the nursing field with a logical adaptation into the PT profession.

Other suggestions may be based on the results of this study on the respondents' opinion of the most successful strategies:

1. attractive benefit package,

2. student program,

3. professional development opportunities (i.e., career ladder, participative management, clinical expertise, empowerment, flexibility and autonomy).

\section{Limitations of the Study}

Limitations of this study are that it did not look at the opinions of the PT staff on issues related with recruitment and retention, and it ignored turnover rates, future staffing trends and issues related with managed care. 
Another limitation was that many available recruitment and retention strategies were not added to the survey. Also, it is possible that there was confusion by not defining strategies in more detail. It is also possible that it would have been better to select and define ways of measuring the use of strategies by requesting the advice of a human resource specialist in the health care field.

\section{Suggestions for Future Research}

The results of this study suggest numerous relevant topics for additional research. Examples are: analysis of PT staffing trends in hospitals settings and comparison of results of this study with new research on future PT recruitment and retention trends in the new health care environment of managed care. Future research could survey the staff PTs on what attracts them to work in hospital settings. Another topic of investigation is on future trends in student programs; their organization, cost and effectiveness. Results from this study indicated that student employment was viewed as a successful strategy. Therefore it is crucial to know what will be the essential components of a "good" student program, and how to organize and manage it in order to be successful in student employment. It is also important to gather information on cost of program and feasibility of implementing it. One of the most important strategies used to successfully recruit and retain PTs was "attractive benefit package." It would be very interesting if we could research what constitutes an attractive benefit package for physical therapists employed in 
hospital settings. Other suggestions for future research are: a study on rehabilitation administrators and rehabilitation services; including demographic characteristics of administrators and work environment, goals for rehabilitation services and opinions on the impact of managed care on rehabilitation personnel. It would be interesting to learn their opinions on personnel management, more specifically rehabilitation personnel, as well as future goals and the impact of managed care on rehabilitation staffing and the impact on quality care; and the analysis of the expectations of experienced PTs working in hospital settings in relationship with professional development opportunities. A common reason for PTs leaving hospital is lack of professional opportunities. A study on this topic would enlighten hospital administrators, PT department managers and human resources administrators on what experienced PTs are looking for in the hospital setting.

\section{Conclusion}

The majority of the respondents to this descriptive research reported having problems with the recruitment and retention of PTs in hospital settings.

Attractive benefit package, interdisciplinary teams, competitive salaries adjusted in a yearly basis and student employment are common strategies used nationwide to recruit and retain PTs in general mid-to-large size hospitals. Sign-on-bonus, incentive pay programs recruitment and retention committee and temporary staffing are not common strategies. 
Attractive benefit package, "good" student program and professional development opportunities were in the respondents' opinions, the most successful strategies used to aid in the recruitment and retention of PTs in hospital settings in 1994.

The results of the survey showed that most of the respondents were female PTs with professional title, "Chief" or "Director" of Physical Therapy. The average years of managerial experience was 8.5 and the mean age was 40.9 years. Of those respondents that were PTs, the great majority showed no formal business or management education and their highest level of education was Bachelor of Science in Physical Therapy.

Respondents formally educated in the business/management field used strategies such as flexibility and sign on bonus, as "key" strategies to recruit and retain PTs. The oldest group of respondents (35-45 years old) and male respondents tended not to use temporary staffing.

Hospital administrators need to increase their awareness toward the adverse effects of the shortage and its negative consequences among the staff that remains employed in hospital settings. They should learn from the solutions adopted by the nursing field, since there is significantly more published research, and extrapolate them and adapt them according to the staff needs. Hospitals administrators, human resource managers and PT or rehabilitation administrators must also research their staffing trends and evaluate strategies currently used to recruit and retain PTs and also evaluate its efficacy in order to become successful in developing a stable working environment with a more positive impact on patient care. 


\section{List of References:}

Adamski, M. \& Hagen, B. (1990). Using technology to create a professional environment for recruitment and retention. Nursing Administration Quarterly, 14(4) 32-37.

AHA (American Hospital Association) (1991). Annual Survey of Human Resources.

Chicago, IL.

Ames et al. (1992). Assessing Work Retention Issues. Journal of Nursing Administration, $\underline{22}(4), 37-41$.

APTA (American Physical Therapy Association) (1992). Recruitment and Retention of Physical Therapists in Hospital-Based Practice. Alexandria, VA.

Bauer, M., Cherry, R.J., Clutter, P., Nelson, B. \& Sandwell, A. (1993). Retention Can be Improved. Nursing Management, 24(10), 39-46.

Birritteri, A. (1993). Hospital Shortage in Remission. The New Jersey Business Magazine, 39(8), 22-24, 48-49. 
Breske, S. (1993). Joining Forces 10 Hospitals Join Forces to Bring PTs to Dayton. Advance for Physical Therapists.

Corley, M.C., Farley, B., Geddes, N., Goodloe, L. \& Green, P. (1994). The Clinical Ladder Impact on Nurse Satisfaction and Turnover. Journal of Nursing Administration, 24(2), 42-48.

Haferty, F.W. \& Goldberg, H.I. (1986). Educational Strategies for Targeted Retention of Nonphysician Health Care Providers. Health Services Research, 21 (1), 107-125.

Freda, M. (1991). Retaining Occupational Therapists in Rehabilitation Settings: Influential Factors. The American Journal of Occupational Therapy, 46(3), 240248.

Khan, K. \& Konsones, D. (1992). Empowerment: charting for retention. Nursing Management, $\underline{23}(8), 64-84$.

Koska, M.T. (1989). Rehabilitation Growth Fuels PT Shortages. Hospitals, 63(5), 32 . 
Murphy, J. (1995). Watching Recruitment Trends in PT Corporations. Advance for Physical Therapists, $\underline{6}(20), 6 \& 20$.

Norusis, M.J. (1992). SPSS-PC+ [Computer Program]. Chicago, IL:SPSS, Inc.

Novell Perfect Office $(1993,1994)$. Quattro Pro [Computer Program]. Novell Inc., Orem, Utah.

Russell, T. (1990). The PT Personnel Shortage. Clinical Management, 10(2), 15.

Russell, T., Seidman, R. \& Williams, S. (1990). The PT Personnel Shortage. Clinical Management, $\underline{10}(2), 18-23$.

Shanahan, M.M. (1993). A comparative analysis of recruitment and retention of health care professionals. Health Care Management, $18(3), 41-51$.

Strakal, G. (1990). Tailoring an Incentive Program. Clinical Management, 10(2)16-17.

Strakal, G. \& Egli, H.J. (1993). Career Ladder For Allied Health Professionals._Physical Therapy Forum, 4, 4-9. 
U.S. Department of Labor (1993). Fastest Growing Occupations. Bureau of Labor Statistics, Occupational Employment, Monthly Labor Review.

U.S. Directory Service (1995). The Hospital Phone Book. 
Appendix A: Copy of Cover Letter and Survey Instrument 
Date: $3 / 15 / 95$

From: Laura Burgos, PT

Graduate Student

Department of Physical Therapy

Florida International University

University Park Campus

Miami, Florida 33199

To: $\quad$ Physical Therapy Director / Manager

Dear Colleague,

I am a Master's degree candidate in Physical Therapy here at Florida International University, and I am also on the staff of a large general hospital. I have become interested in the problem of recruitment and retention of physical therapists in general hospital settings, and I am in the process of completing a thesis about this topic.

In order to complete my thesis, I need to learn about the recruitment and retention strategies currently in use across the country.

Would you be so kind as to take a few minutes of your time to complete the attached survey? It should take less than 5 minutes.

Your responses will be completely anonymous. You will find no identifying codes on this letter, the survey, or the return envelope. If you would like a copy of the results of the survey, or if you have any questions, please feel free to call me at 305/674-2844 between 9 and 4:30 EST, or write to me at the address at the bottom of this page.

This survey is being sent to a relatively small group of physical therapists, so every response is important to the success of my project. I thank you in advance for your time and consideration.

Laura Burgos, PT 
1. What is your professional title?

2. What is your gender?

Male Female

3. How old are you? ___ Years

4. Which word best describes your hospital?

$$
\begin{aligned}
& \text { Private, not for profit } \\
& \text { Private, investor owned } \\
& \text { State or local government owned } \\
& \text { Federal, Veterans Administration } \\
& \text { Other }
\end{aligned}
$$

5. What is your inpatient capacity? _ Beds

6. Which state are you located in?

7. Are you a Physical Therapist? __ Yes __ No

8. If you are a Physical Therapist, what is your level of education?

Certificate
Bachelors Degree
Masters Degree
Doctoral Degree
Other, please specify:

9. If you are not a Physical Therapist, what is your professional field?

10. Do you have a degree in business or management? __ Yes _ No If so, what is your degree? _ BBA _ MBA _

11. How many years have you been directing / managing a PT department? _ Years

12. How many budgeted physical therapist positions do you currently have in your department?

13. How many of these budgeted positions are currently vacant?

14. Have you had a problem with the recruitment and retention of physical therapists within the last year? Yes No 
Please check either true or false for items 15 through 23.

15. _ True _ False We use a formal career ladder policy to promote our PTs.

16. _. True _ False We offer an attractive benefit package.

17. True False We have incentive pay programs.

18. True False We have a flexible scheduling program for our PT staff.

19. _ True _ False We have interdisciplinary teams.

20. _ True _ False We have specialized clinical assignments.

21. _ True _ False We pay competitive salaries which are adjusted on a yearly basis.

22. _ True _ False We offer sign-on bonuses.

23. _ True _ False We currently have a recruitment and retention committee within our department.

Please check the appropriate category for items 24 through 28 .

\section{Never Seldom Occasionally Frequently Always}

24. We use contract PT services.

25. We use on-call, per diem PTs

26. We have a scholarship and/or forgivable loan program.

27. We use aggressive recruitment advertising

28. We hire students that performed their clinical affiliations with us.

29. What has been the most successful strategy you have used to aid in recruitment and retention of PTs? Why?

Thank you for participating in my study. Please place this survey in the enclosed pre-paid envelope and return it at your earliest convenience. If you would like a copy of the results, please write your name and address on the back of this page. 